10.1590/S1414-40772017000300002

\title{
Para uma política pública de internacionalização para o ensino superior no Brasil
}

\author{
José Alberto Antunes de Miranda
}

Luciane Stallivieri

Resumo: A internacionalização das Instituições de Ensino Superior é um tema cada vez mais recorrente nos fóruns internacionais de discussão sobre os rumos da educação mundial e, especialmente, nos últimos anos, no Brasil. Percebe-se que, mesmo presente nos mais privilegiados espaços de reflexão, com atores de alto poder decisório, o tema ainda precisa de amadurecimento, de sistematização de ações, e, principalmente, da elaboração conjunta de políticas públicas de Estado que possam dar um direcionamento para a internacionalização do sistema de Ensino Superior, viável e necessária para o Brasil. A exemplo de outros países, o Brasil também necessita escrever a sua política de internacionalização, com o objetivo de ser protagonista das mudanças do cenário da educação mundial e não apenas observador dos novos movimentos. Tendo presente o modelo de outros países, cujas políticas de internacionalização são públicas e divulgadas, o presente estudo buscou investigar a existência de documentos governamentais que apresentem as políticas para a internacionalização das Instituições de Ensino Superior brasileiras, com vistas ao desenvolvimento econômico, científico e tecnológico do país. Realizou-se um estudo, com base em pesquisa bibliográfica e documental de ações do Governo brasileiro, com relação ao tema da internacionalização do Ensino Superior, bem como em bases de dados de Governos da Alemanha, Colômbia, Espanha, Finlândia e Reino Unido, que comprovadamente possuem altos índices de internacionalização educacional. Detectou-se que o Brasil ainda precisa aprofundar o diálogo entre os atores envolvidos, promover discussões específicas e elaborar suas próprias políticas, dado o número ainda insuficiente de documentos governamentais com essa finalidade. Para a elaboração dessas políticas, foram analisados alguns parâmetros a serem considerados, tais como: identidade, institucionalidade, visibilidade, referência e sustentabilidade.

Palavras-chave: Internacionalização. Educação Superior. Políticas públicas. Brasil.

\section{For a public policy of internationalization of higher education in Brazil}

Abstract: The internationalization of Higher Education Institutions is an increasingly recurring theme in international forums, which discuss the future of global education and, especially in recent years, in Brazil. It is noticed that, even in the most privileged spaces for discussion, with high decision-making actors, the subject still needs to be matured; it needs the systematization of actions, and especially the joint development of public policies that can give a direction to the internationalization of higher education system, feasible and necessary for Brazil. Like other countries, Brazil also needs to write its internationalization policy, in order to be protagonist of the changes in the landscape of global education and not just an observer of the new movements. Bearing in mind the model of other countries which internationalization policies are public and published, this study sought to investigate the existence of governmental documents that present policies for the internationalization of Brazilian higher education institutions, with regard to economic, scientific and technological development of the country. This study was conducted, based on bibliographic and documentary research of the Brazilian Government on the issue of internationalization of higher education, as well as Governmental databases of Germany, Colombia, Spain, Finland and United Kingdom, once these countries are known to have high levels of educational internationalization. It was found that Brazil still needs to deepen the dialogue between the actors involved, to promote specific discussions and develop its own policies, as until now there are no sufficient documents for this purpose. For the development of these policies, some parameters were highlighted to be considered, such as identity, institutionalization, visibility, reference and sustainability.

Key words: Internationalization. Higher Education. Public policies. Brazil. 


\section{Introdução}

A internacionalização das Instituições de Ensino Superior (IES) brasileiras tem sido, nos últimos anos, tema recorrente no âmbito das discussões sobre educação superior. Essa discussão reforça a necessidade da construção de uma política pública (SECCHI, 2013) para a internacionalização do sistema de Ensino Superior no Brasil, que defina as grandes linhas que apoiam a decisão e a ação (SECCHI, 2013), e a definição do caminho a seguir, que precisa ser construída pelo diálogo entre os principais atores envolvidos nesse processo, ou seja: as Instituições de Ensino Superior, o governo brasileiro e as empresas.

Historicamente, esse tema tem sido conduzido por algumas universidades brasileiras e o governo, no esforço de buscar projetos de colaboração em pesquisa e intercâmbio de estudantes com outros países, porém de forma nem sempre articulada.

Em função das conexões que tem com o desenvolvimento econômico e com a diplomacia pública, a educação internacional, no Brasil, precisa receber mais atenção, especialmente no que diz respeito à definição dos interesses nacionais frente ao seu processo de internacionalização. As decisões sobre formação de talentos para o futuro do país, uma agenda de cooperação internacional em matéria de transferência de conhecimento, a contribuição nacional aos desafios mundiais e a vinculação das atividades de internacionalização das agendas regionais são questões que o país precisa tratar de forma mais propositiva.

A internacionalização constitui, hoje, uma das forças que mais impacta e define a educação superior, pois é um dos mais importantes desafios frente ao novo século. As trocas internacionais e interculturais entre as Instituições de Ensino Superior no mundo foram ampliadas e continuam em expansão (WIT, 2002; ALTBACH; KNIGHT, 2007; HUDZIK, 2011; DEARDORF, 2012). Este século exige que as universidades repensem o seu papel diante da sociedade, como instituições que abrigam diferentes valores e opiniões e que destacam o caráter universal do conhecimento.

Nesse cenário, o objetivo deste artigo é salientar a necessidade de ampliar a discussão sobre o processo de internacionalização do sistema de Ensino Superior brasileiro, a partir da conveniência para o país em elaborar uma política pública - entendendo-a como uma forma de atuação dos Estado, seja através de ações geradas no seio do governo, ou originadas por forças sociais (OFFE, 1984) - que indique um caminho a ser seguido pelas Instituições de Ensino Superior brasileiras, considerando os interesses estratégicos de inserção e de cooperação internacional frente a um mundo globalizado. 
$\mathrm{O}$ artigo evidencia a inexistência de documentos do governo brasileiro que explorem, de forma mais clara, a internacionalização da educação superior e que tratem a mesma como uma política pública. Trata-se de um estudo que se propõe a analisar alguns parâmetros (MANJARRÉS; GONZÁLEZ, 2014) que poderão nortear as discussões no estabelecimento dessas políticas, com o objetivo de colaborar para o posicionamento institucional das IES brasileiras no cenário da educação mundial. Documentos referenciais elaborados por organismos governamentais e Ministérios de Educação de países com elevado grau de internacionalização são analisados, a fim de fomentar uma discussão madura sobre o tema em relevo.

\section{Referencial teórico}

A promoção da internacionalização da educação superior, no âmbito governamental, necessita ter um significado estratégico para o país. A abertura das universidades brasileiras para o mundo precisa ser de mão dupla, no sentido de levá-las à modernização e à inovação, a partir da cooperação internacional entre diferentes países e, consequentemente, buscar a promoção do desenvolvimento nacional.

Esforços para promover a internacionalização da educação superior objetivam fazer com que a comunidade acadêmica tenha condições de compreender, apreciar e se articular ante a interdependência entre os Estados em diversas áreas como o meio ambiente, a economia, a cultura e o social, dentre outras. Da mesma forma, esses esforços devem preparar a comunidade acadêmica para atuar em um contexto internacional e intercultural cada vez mais presente em um mundo globalizado (DEARDORF et al., 2012; SALMI, 2014). As instituições de Ensino Superior têm a oportunidade e a responsabilidade, através do ensino e da pesquisa, de aumentar a compreensão desse fenômeno que afeta as nações (WIT, 2002).

A chamada para a internacionalização das universidades corresponde a motivações que frequentemente não são explícitas, estão gradualmente mudando e refletem o ambiente competitivo internacional da sociedade do conhecimento, reforçando, ainda mais, o papel da educação superior na indústria do conhecimento (LASTRES; FERRAZ, 1999). A internacionalização é parte da resposta e é composta por diferentes estratégias, políticas e atividades desenvolvidas por governos e instituições, como as universidades. A construção de uma política de internacionalização para a educação superior precisa contemplar a diversidade de enfoques nas ações dos atores nacionais que promovem a internacionalização (HUDZIK, 2011).

A internacionalização exige um processo de análise do estado da educação superior, do contexto socioeconômico da nação e das tendências globais, assim como uma revisão dos 
desafios do sistema em matéria de qualidade, formação de recursos humanos, gestão, uso dos sistemas de informação, produção científica e investigativa, competências em línguas estrangeiras, fortalecimento das instituições de Ensino Superior e flexibilização normativa, dentre outros (CROSS; MHLANGA; OJO, 2011).

O Brasil vive um momento em que a discussão sobre a necessidade da internacionalização da educação superior atinge um momento crucial, quando estão envolvidos os principais atores desse processo, como órgãos de governo, agências de fomento e entidades que representam a área da educação no país. ${ }^{1}$ Esse momento exige a identificação da existência, ou não, de fundamentos e definições para a construção de políticas públicas para a internacionalização do sistema de Ensino Superior.

Manjarrés e González (2014) evidenciam que elementos importantes necessitam ser definidos de forma mais clara, a fim de auxiliarem no estabelecimento de políticas para a internacionalização e, para tanto, propõem alguns parâmetros:

a) a necessidade de uma política pública que responda e contribua para a construção de um projeto de país, de acordo com as normas brasileiras, com a política nacional e internacional - um parâmetro de identidade - ou seja, o que se quer com a internacionalização;

b) a articulação de iniciativas e estratégias de diferentes atores e a ampliação dos esforços para desenhar conjuntamente uma proposta de internacionalização do sistema de educação superior, necessária para o desenvolvimento do país - um parâmetro de institucionalidade;

c) o reconhecimento dos avanços e dos desafios do país em melhorar sua imagem no Exterior, de forma a dar visibilidade às fortalezas do seu sistema de educação superior e para garantir uma oferta educativa de qualidade - parâmetro de visibilidade;

d) o desafio de transformar o sistema educativo a partir do reconhecimento das práticas exitosas de outros países e de nosso próprio país por meio das Instituições de Ensino Superior e de revisar os mecanismos internos para sistematizar, viabilizar e avaliar os avanços da internacionalização no país - parâmetro de referência;

e) a necessidade de dar continuidade e de ampliar o alcance dos programas e das iniciativas que estão sendo construídas, para fomentar a internacionalização da educação superior, assegurando a sua manutenção - parâmetro de sustentabilidade.

\footnotetext{
${ }^{1}$ Entidades como a Associação Brasileira de Educação Internacional (FAUBAI); o Conselho de Reitores das Universidades Brasileiras (CRUB); Consórcio das Universidades Comunitárias Gaúchas (COMUNG); Associação Brasileira das Universidades Comunitárias (ABRUC); a Associação Nacional de Educação Católica no Brasil (ANEC); o Ministério da Educação (MEC), a Coordenação de Aperfeiçoamento de Pessoal de Nível Superior (CAPES), o Conselho Nacional de Desenvolvimento Científico e Tecnológico (CNPq) e o Ministério de Relações Exteriores (MRE), dentre outros realizam essas discussões ante os desafios para a internacionalização da educação superior no Brasil.
} 


\section{Procedimentos metodológicos}

A abordagem deste estudo é qualitativa, pois foi considerada a forma mais adequada para entender a natureza do fenômeno estudado - políticas públicas e internacionalização do Ensino Superior. Os estudos que utilizam a metodologia qualitativa podem descrever a complexidade de determinado problema e analisar a interação entre determinadas variáveis, compreender e classificar processos dinâmicos vividos por determinados atores (RICHARDSON, 1999).

Para a elaboração do referencial teórico, procedeu-se uma revisão da literatura disponível nas bases de dados (Google Scholar; Ebscohost; SciELO), buscando-se as teses e dissertações, bem como artigos científicos publicados sobre o tema no Brasil e no exterior. Nos bancos de dados e sites governamentais, fez-se uma pesquisa bibliográfica e documental, com coleta de dados secundários, buscando-se identificar os modelos de internacionalização e a forma como alguns países e como o Brasil elaboraram e estão elaborando as suas políticas públicas de internacionalização para o Ensino Superior.

De acordo com Gil (2010), a pesquisa documental vale-se de toda sorte de documentos, elaborados com finalidades diversas. A modalidade mais comum de documento é a constituída por um texto escrito, mas estão se tornando cada vez mais frequentes os documentos eletrônicos, disponíveis sob os mais diferentes formatos. O conceito de documento, por sua vez, é bastante amplo, já que pode ser construído por qualquer objeto capaz de comprovar algum fato ou acontecimento. Ainda segundo o mesmo autor, os documentos mais utilizados nas pesquisas, estão: documentos institucionais, mantidos em arquivos de empresas, órgãos públicos e outras organizações (GIL, 2010).

Sendo assim, para este estudo, avançou-se com mais uma etapa da pesquisa que consistiu na identificação dos países com comprovado grau de internacionalização, sendo suficientes/satisfatórios para exemplos de análise: Alemanha, Colômbia, Espanha, Finlândia e Reino Unido. Feita a seleção dos países, partiu-se para a identificação de documentos governamentais que descrevessem as ações de políticas públicas adotadas para o desenvolvimento da internacionalização do Ensino Superior. Essa etapa foi realizada através de revisão bibliográfica e análise documental do material disponibilizado nos sites governamentais dos países que são representativos nos avanços da cooperação internacional e no que diz respeito à existência de definições e de políticas claras para as ações de internacionalização, ou seja, The Federal Government and the Länder da Alemanha, Ministerio de Educación Nacional da Colômbia, 
Ministerio de Educación, Cultura e Deporte da Espanha, Ministry of Education da Finlândia e The Government of the United Kingdom, Governo do Reino Unido.

Da mesma, forma, investigou-se documentos do Governo brasileiro, disponibilizados ao longo dos últimos anos, que mencionam a internacionalização da educação superior, especialmente nos Ministérios da Educação (MEC), Ministério da Ciência e Tecnologia (MCT) e Ministério das Relações Exteriores (MRE), focando especificamente as agências de fomento e de cooperação internacional, Capes e Cnpq. No caso do Brasil, analisou-se a Lei de Diretrizes e Bases da Educacão Nacional, os Planos Nacionais de Educacão, o Plano Nacional de Pósgraduacão de 2011-2020 e o Programa Ciências Sem Fronteiras.

\section{Quadro 1 - Etapas da pesquisa e fontes de coletas de dados}

\begin{tabular}{|l|l|}
\hline \multicolumn{1}{|c|}{ Etapas da pesquisa } & \multicolumn{1}{c|}{ Fontes de coletas de dados } \\
\hline Revisão sistemática da literatura & Bases de dados (Google Scholar, Ebscohost, Scielo) \\
\hline Elaboração do referencial teórico & Teses, dissertações, artigos científicos selecionados \\
\hline Identificação e seleção dos países para análise & Sites, documentos governamentais \\
\hline Seleção e análise dos documentos governamentais & $\begin{array}{l}\text { Sites dos governos da Alemanha, Colômbia, Espanha, Fin- } \\
\text { lândia, Reino Unido e do Brasil. }\end{array}$ \\
\hline
\end{tabular}

Fonte: Elaborada pelos autores (2015).

Após a coleta de dados feita por meio do levantamento bibliográfico e documental, procedeu-se a análise do material selecionado, possibilitando a criação das categorias de análise e identificando os parâmetros para a elaboração de uma proposta de política pública para a internacioalização do Ensino Superior brasileiro.

\section{Análise de resultados}

De acordo com os parâmetros apresentados nos documentos governamentais dos países pesquisados, procurou-se estabelecer algumas relações e identificar ações desenvolvidas pelo Governo brasileiro, no sentido de definir alguns direcionamentos que possam dar suporte ao desenho de uma política pública de internacionalização para o sistema de Ensino Superior.

\subsection{Parâmetro de identidade}

Com relação ao primeiro critério, que enfoca os aspectos de identidade nacional e internacional da política pública, considera-se que a internacionalização esteja ligada a outros elementos identitários. A construção de uma política de internacionalização precisa discutir a 
vocação da internacionalização para favorecer a compreensão contextual da cultura, incluindo os contextos políticos e sociais (DEARDORF et al., 2012).

A estruturação de uma política para a internacionalização da educação superior exige elementos de política pública que respondam à construção de um projeto de Estado (MANJARRÉS; GONZÁLEZ, 2014), lembrando que a política pública se insere entre uma situação existente e outra desejada (FRANCO; COHEN, 1992). Identifica-se que há motivações econômicas, políticas, acadêmicas e sócio culturais no suporte ao desenvolvimento econômico e tecnológico do país, mas a indicação de como a internacionalização da educação superior, a partir dessas motivações, contribuirá no fortalecimento da posição internacional do Brasil no sistema internacional ainda é frágil.

Observando-se os principais documentos governamentais do Brasil, que suscitam em algum momento a preocupação com a internacionalização da educação superior, é a partir do do atual Plano Nacional de Educacão e, mais pontualmente, a partir do Plano Nacional de Pós-graduacão de 2011-2020 e do documento do Programa Ciências em Fronteiras que se pode perceber a internacionalizacão da educação superior como um desejo por parte do governo brasileiro de forma mais pontual. Ainda assim, não está claro o que se deseja com a internacionalização em termos de política pública, que defina as grandes linhas que apoiam a decisão e a ação do país em termos mais propositivos.

Na perspectiva de Franco e outros (2010) os Planos Nacionais de Educação anteriores, principalmente nos anos de 1960 e 1970, tinham a preocupação de formação de doutores e de pesquisadores no exterior, de forma que retornassem ao país com experiência e que fossem inseridos na pós-graduação brasileira. ${ }^{2}$

O próprio Plano Nacional de Pós-graduação 2011-2020, conforme já apontado por Franco e outros (2010), traz a preocupação com a expansão da educação superior brasileira, indicando que essa expansão por meio da internacionalização acontece nas instituições, nos cursos e no sistema como um todo. A preocupação se daria de uma forma transversal sendo identificadas pela expansão numérica, pela via de ampliação de alternativas, pela necessidade de expansão na produção do conhecimento sobre a influência de internacionalização das universidades (FRANCO et al., 2010). O Plano Nacional de Pós-graduação 2011-2020 evidencia

\footnotetext{
2 A cooperação internacional trata-se de uma atividade tradicional que tem lugar no CNPq desde a sua criação em 1951. Atualmente, é coordenada e implementada na Assessoria de Cooperação Internacional ASCIN, ligada diretamente à presidência do CNPq. A ASCIN disponibiliza diferentes mecanismos de financiamento à cooperação internacional para apoiar projetos de pesquisas conjuntas de alta qualidade, mobilidade de pesquisadores e treinamento de pesquisadores e formação de recursos humanos, objetivando a promoção do desenvolvimento científico e tecnológico brasileiro, em consonância com as orientações da Política Nacional de Desenvolvimento Científico e Tecnológico (FRANCO; MOROSINI, 2012).
} 
a preocupação com as políticas de cooperação internacional e de formação de recursos humanos no exterior, mas, em nenhum momento, define uma política pública para a internacionalização da educação superior brasileira a partir de parâmetros pré-definidos. ${ }^{3}$

Observa-se ações propositivas mais pontuais por parte do Brasil na América Latina e na África ao longo dos últimos anos, onde se identifica a obtenção de padrões internacionais para os programas de pós-graduação, que formam uma dimensão internacional e intercultural para a pesquisa e o ensino, via ações do Ministério da Educação e do Ministério de Relações Exteriores. Entretanto, pode-se observar, com bem menor intensidade, ações propositivas nas articulações com o hemisfério Norte, onde o país, com frequência, absorve o que está sendo oferecido e não o que é desejável e necessário para o desenvolvimento de áreas estratégicas para o país. ${ }^{4}$

A Espanha, por exemplo, buscando fortalecer a identidade do sistema de educação superior espanhol, desenhou sua política de internacionalização, publicada no documento: Estrategia para la internacionalización de las universidades españolas 2015 - 2020. O documento está pautado no objetivo de

Consolidar un sistema universitário fuerte e internacionalmente atractivo que promueva la movilidad de entrada y salida de los mejores estudiantes, profesores, investigadores y personal de administración y servicios, lacalidad educativa, el potencial del español como idioma para la educación superior, la internacionalización de los programas formativos y las actividades de $\mathrm{I}+\mathrm{D}+\mathrm{i}$, contribuyendo a la mejora del atractivo y de la competitividad internacional de España, así como al desarrollo socioeconómico de su entorno próximo basado en el conocimiento (ESPANHA, 2014).

\subsection{Parâmetro da institucionalidade}

O critério de institucionalidade traz o desafio para o país em articular iniciativas e estratégias dos diferentes atores envolvidos para aumentar os esforços que favoreçam a internacionalização do sistema de educação superior (MANJARRÉS; GONZÁLEZ, 2014).

\footnotetext{
${ }^{3}$ De acordo com o Plano Nacional de Pós-graduação 2011-2020 a cooperação internacional deveria: destacar o aprimoramento do sistema nacional de pós-graduação, considerando o avanço do conhecimento; promover a inserção no futuro Plano Nacional de Desenvolvimento Econômico e Social do país; estimular a cooperação internacional por intermédio das universidades, de tal forma que o intercâmbio entre alunos e professores fosse institucionalizado, permitindo inclusive a apresentação de projetos de captação de recursos junto às agências de fomento internacionais; ampliar o atual modelo de parceria institucional, dentro de uma relação de reciprocidade e simetria entre instituições nacionais e estrangeiras. A partir do intercâmbio recíproco de alunos e professores em projetos de pesquisa específicos, bolsas-sanduíche para os alunos além da oferta de estágios.

${ }^{4}$ Com o objetivo implícito de aumentar sua inserção internacional, a ação do Brasil não se dá pela oferta de recursos líquidos aos países em desenvolvimento, mas sim na oferta do conjunto de conhecimentos e soluções técnicas acumuladas, frutos de seu desenvolvimento científico e tecnológico. O país se utiliza muito da "Diplomacia Solidária", conceito que designa a disponibilização a outros países das experiências e conhecimentos de instituições nacionais especializadas sem que isso implique condições ou ingerências na soberania do país parceiro.
} 
O Ministério de Relações Exteriores (MRE), o Ministério de Ciência e Tecnologia (MCT) e o Ministério da Educação (MEC), foram nos últimos cinco anos os atores mais importantes no processo de internacionalização da educação superior brasileira e são os agentes principais no âmbito da produção de normas para área (BRASIL, 2008, 2013, 2014). ${ }^{5}$ É possível observar a evolução na oferta de programas e nos acordos internacionais firmados pelas principais agências estatais de fomento nacionais, como a Capes, que está vinculada ao Ministério da Educação, o CNPq, vinculado ao Ministério da Ciência e Tecnologia e a Agência Brasileira de Cooperação (ABC), vinculada ao Ministério de Relações Exteriores - Itamaraty, que é responsável pela cooperação técnica bilateral e multilateral em todas as áreas do conhecimento, como pode ser analisado no Quadro 2.

Quadro 2 - Síntese do Número de Acordos de Cooperação firmado pelas agências de cooperação internacional brasileiras, somente nos últimos cinco anos (2010-2015)

\begin{tabular}{|l|c|lc|c|}
\hline $\begin{array}{c}\text { Ministério e } \\
\text { Agência de } \\
\text { Cooperação }\end{array}$ & $\begin{array}{c}\text { Número de } \\
\text { Acordos } \\
\text { Firmados }\end{array}$ & Objetivos dos Acordos de Cooperação Internacional & \multicolumn{1}{c|}{$\begin{array}{c}\text { Distribuição por } \\
\text { Região }\end{array}$} \\
\hline MRE - ABC & 80 & $\begin{array}{l}\text { Os acordos de cooperação bilateral, mantidos pela ABC, visam } \\
\text { o desenvolvimento da Cooperação Técnica, Científica e Tecno- } \\
\text { lógica. }\end{array}$ & $\begin{array}{l}\text { América Latina e } \\
\text { América do Norte, } \\
\text { Europa, Ásia e África. }\end{array}$ \\
\hline $\begin{array}{l}\text { MEC - Ca- } \\
\text { pes }\end{array}$ & 67 & $\begin{array}{l}\text { Os acordos de cooperação bilateral, mantidos pela Capes, } \\
\text { buscam o desenvolvimento das atividades da pós-graduação } \\
\text { brasileira no contexto mundial e o apoio aos grupos de pesquisa } \\
\text { brasileiros por meio do intercâmbio internacional. }\end{array}$ & $\begin{array}{l}\text { América Latina e } \\
\text { Europa e Ásica do Norte, }\end{array}$ \\
\hline MCT - CNPq & 50 & $\begin{array}{l}\text { Os acordos de cooperação bilateral, mantidos pelo CNPq, apoi- } \\
\text { am principalmente a mobilidade de pesquisadores no âmbito de } \\
\text { projetos conjuntos de pesquisa, desenvolvimento e inovação, } \\
\text { em áreas preferenciais, definidas de comum acordo com as } \\
\text { instituições financiadoras estrangeiras. }\end{array}$ & $\begin{array}{l}\text { América Latina e } \\
\text { América do Norte, } \\
\text { Europa e Ásia. }\end{array}$ \\
\hline
\end{tabular}

Fonte: Elaborado pelos autores a partir de Brasil (2008, 2013, 2014).

No âmbito do Itamaraty, a internacionalização da educação superior tem sido um dos temas que diversificaram as relações internacionais nas últimas décadas. É parte de uma agenda positiva, pois o tema está ligado ao desenvolvimento econômico e social, à cooperação internacional e à promoção da convivência cultural das sociedades.

\footnotetext{
5 As ações do MEC são implementadas pela Secretaria do Ensino Superior (SESU), responsável por planejar, orientar, coordenar e supervisionar o processo de formação e implementação da Política Nacional da Educação Superior, pela Capes - encarregada da qualificação dos professores da educação superior, da avaliação e suporte aos programas de pós-graduação e pela concessão de bolsas - e pelo Conselho Nacional de Educação (CNE), criado no ano de 1995 e encarregado de autorizar a criação de novas instituições e cursos, estabelecer as regras sobre currículos, questões relativas à educação a distância, mecanismos de avaliação, credenciamento e recredenciamento de instituições, validação de diplomas e todas as ações complementares à implementação da Lei de Diretrizes e Bases (LDB). O MEC conta com dois organismos responsáveis pelas relações internacionais: a Assessoria Internacional da SESU e a Assessoria para Assuntos Internacionais do gabinete do Ministro.
} 
De acordo com a chefe da Divisão de Temas Educacionais do Ministério de Relações Exteriores, Conselheira Almerinda de Carvalho ${ }^{6}$, a internacionalização da educação superior tem impacto na inserção internacional do país em três vertentes: a) na econômica, pois a educação qualifica a mão de obra que atua no desenvolvimento do país; b) na política, pois a cooperação educacional representa parte de uma agenda positiva da política externa ao promover a aproximação entre os estados. A visão do Brasil, como um país que age com base em princípios de solidariedade, favorece a formação de uma cultura de paz, compreensão mútua e confiança entre os povos; e c) na cultural, por meio da convivência, do aprendizado de outro idioma e da troca de experiências, que contribuem para o estreitamento de laços com outras sociedades (CARVALHO, 2014).

A Capes tem trabalhado por uma internacionalização verdadeiramente acadêmica do sistema universitário brasileiro e é respeitada no âmbito internacional como agência eficiente nesse processo. Um dos principais motivos de criação da Capes, em 1951, foi de ultrapassar as lacunas do sistema educativo, vis-à-vis às grandes potências, através da cooperação científica internacional ${ }^{7}$ (CANEDO; GARCIA, 2004-2005). ${ }^{8}$

Com a evolução dos programas de pós-graduação, ao longo dos anos, no Brasil, se estabeleceram condições para que a internacionalização deixasse de ser implementada sob uma perspectiva mais receptora e passiva, evoluindo até um modelo baseado em uma experiência mais igualitária, desenvolvida por grupos interinstitucionais (LAUS; MOROSINI, 2005).

Através do apoio aos projetos inseridos dentro de um programa e uma demanda mais induzida, nem sempre alinhados com as grandes prioridades do desenvolvimento nacional,

\footnotetext{
${ }^{6}$ Conferência proferida sobre Cooperação Internacional em Educação Superior, durante a realização do Seminário: Internacionalização: Desafio para Universidade, na Pontifícia Universidade Católica do Rio Grande do Sul (PUC-RS).

${ }^{7}$ No âmbito do MEC, a Capes, que é uma fundação pública, possui sua Coordenação Geral da Cooperação Internacional (CGCI), encarregada pelas atividades de pós-graduação brasileira no contexto mundial e pelo Programa Estudante Convênio de Pós-Graduação (PEC-PG), no que se refere às bolsas de doutorado e àquelas de Mestrado para os estudantes de Timor Leste, concedidas por esse Programa, já que as concedidas para países africanos e latino-americanos estão a cargo do Conselho Nacional de Desenvolvimento Científico e Tecnológico $(\mathrm{CNPq})$. Ainda recentemente, a Capes assumiu a responsabilidade de gerir o programa Ciências sem Fronteiras.

8 A CAPES, instituiu no final de 2007 a Diretoria de Relações Internacionais, sendo responsável pelos programas de bolsas no exterior (CGBE) e cooperação internacional (CGCI). Foram incrementadas a cooperação com diversas agências congêneres de outros países, visando à concessão de bolsas em parceria e de maneira induzida, em torno não apenas de solicitações individuais, como também a partir de demandas de grupos de pesquisa e instituições de ensino superior e ainda de demandas governamentais, estas em especial através da interação com o Ministério das Relações Exteriores. Em 2009, o orçamento da DRI foi superior a R\$ 122 milhões e a previsão orçamentária para 2010 supera $\mathrm{R} \$ 222$ milhões.
} 
essas agências buscam promover a integração dos grupos de pesquisa e a paridade científica entre os parceiros brasileiros e internacionais.

Conforme está apresentado no Quadro 3, a área de conhecimento com maior número de pesquisas é a de Ciências Exatas e da Terra, seguida das Ciências Agrárias e das ciências Biológicas.

Quadro 3 - Relação das áreas de conhecimento com maior número de pesquisas no ano de 2013

\begin{tabular}{|c|c|c|}
\hline Lugar em número de pesquisas & Área de conhecimento & Número de pesquisas \\
\hline $1^{\circ}$ lugar em número de pesquisas & Ciências Exatas e da Terra & 6.301 pesquisas \\
\hline $2^{\circ}$ lugar em número de pesquisas & Ciências Agrárias & 5.711 pesquisas \\
\hline $3^{\circ}$ lugar em número de pesquisas & Ciências Biológicas & 5.499 pesquisas \\
\hline
\end{tabular}

Fonte: Elaborado pelos autores a partir de BRASIL. Conselho Nacional de Desenvolvimento Científico e Tecnológico - CNPQ. Demanda de atendimento. 2013. Disponível em: <http://www.cnpq.br/demanda-eatendimento>. Acesso em: 15 abr. 2015.

O quadro 4 indica as áreas do conhecimento em que o governo brasileiro mais promoveu investimentos ao longo de 2013, estando em primeiro lugar a área de Ciências Exatas e da Terra, seguida pelas Engenharias.

Quadro 4 - Relação das áreas de conhecimento com maior volume de investimentos no ano de 2013

\begin{tabular}{|c|c|c|}
\hline Lugar em volume de investimentos & Área de conhecimento & Valor investido \\
\hline 1ㅇ lugar em volume de investimentos & Ciências Exatas e da Terra & $\mathrm{R} \$ 1.214 .620 .111$ \\
\hline 2ㅇl lugar em volume de investimentos & Engenharias & $\mathrm{R} \$ 1.185 .294 .548$ \\
\hline 3ㅇ lugar em volume de investimentos & Ciências Agrárias & $\mathrm{R} \$ 960.417 .992$ \\
\hline
\end{tabular}

Fonte: Elaborado pelos autores a partir de BRASIL. Conselho Nacional de Desenvolvimento Científico e Tecnológico - CNPQ. Demanda de atendimento. 2013. Disponível em: <http://www.cnpq.br/demanda-eatendimento>. Acesso em: 15 abr. 2015.

Nesse mesmo critério de institucionalidade, identifica-se a necessidade de melhorar a articulação entre os atores que estão trabalhando no processo de internacionalização da educação superior, mais pontualmente a relação das Instituições de Ensino Superior com suas entidades de representação, o governo e as empresas (MANJARRÉS; GONZÁLEZ, 2014), 
observando, fundamentalmente os investimentos realizados em pesquisa em determinadas áreas de conhecimento. ${ }^{9}$

Algumas Instituições de Ensino Superior, que já se encontram em processo mais avançado de internacionalização a partir de sua autonomia, definem individualmente as suas necessidades de acordo com os objetivos consensuais ao plano de metas da instituição (STALLIVIERI, 2004).

Importantes associações brasileiras como a Associação Brasileira de Educação Internacional (FAUBAI), o Conselho de Reitores das Universidades Brasileiras (CRUB), a Associação Nacional de Educação Católica do Brasil (ANEC) e a Associação Brasileira de Universidades Comunitárias (ABRUC) discutem, ainda que de forma não articulada, a internacionalização da educação superior brasileira. É fortemente apontada, por essas entidades, a ausência de uma política pública nacional para a internacionalização do sistema de Ensino Superior, que apresente um documento específico, que contribua com os objetivos estabelecidos em uma política geral de educação superior, que esteja articulada com os interesses estratégicos nacionais para melhor inserção internacional do país e que atenda também às ênfases regionais de um país continental como o Brasil. ${ }^{10}$

Observa-se algumas manifestações de ordem generalista por parte do Ministério da Educação e de suas agências sobre a necessidade da internacionalização, porém o país carece de um documento que consolide um modelo político e socioeconômico, no qual se possa verificar a delimitação de uma política pública estruturada em matéria do que se pretende alcançar com a internacionalização da educação superior.

Na Colômbia, por exemplo, desde 2008, por meio do documento Visão 2032 do Departamento Nacional de Planejamento (DNP), estabeleceu-se uma política de competitividade e produtividade para o país, buscando, com isso, posicionar a Colômbia como um dos três países mais competitivos da América Latina. Essa política contempla programas e ações relacionados com a internacionalização da educação, da ciência e da tecnologia como a formação

\footnotetext{
${ }^{9}$ A discussão sobre o tema internacionalização da educação superior no âmbito das empresas com a universidade e o governo é praticamente inexistente, ainda que o governo tenha tentado isso recentemente com a criação do programa Ciências sem Fronteiras. Um dos graves problemas do envolvimento das empresas nessa discussão é o Estatuto do Estrangeiro, que restringe muito a possibilidade dos estudantes estrangeiros realizarem experiências profissionais nas empresas brasileiras.

${ }^{10}$ Historicamente, alguns ministérios induziram o processo de internacionalização da Educação Superior no país, que se inicia nas universidades públicas e nos Institutos de formação e pesquisa de outros ministérios como o da Agricultura, por meio da Empresa Brasileira de Pesquisa Agropecuário, (Embrapa), do Exército, pelo Instituto Militar do Exército (IME), da Aeronáutica, pelo Instituto Nacional de Pesquisas Espaciais (INPE), da Ciência e Tecnologia, por meio do Instituto Goeldi e se expandiu como uma tendência por todo o Sistema no final dos anos 1990.
} 
de pesquisadores de alto nível, o fomento à mobilidade internacional de pesquisadores, a vinculação a redes internacionais, a projeção internacional da ciência, tecnologia e inovação, a internacionalização da educação superior, o bilinguismo e os espaços transnacionais para o processo de globalização da ciência e da educação ${ }^{11}$ (MANJARRÉS; GONZALEZ, 2014).

$\mathrm{Na}$ Finlândia, da mesma forma, no documento Strategy for the Internacionalization of Higher Education Institutions in Finland (Estratégia de Internacionalização das Instituições de Ensino Superior da Finlândia), para o período 2009-2015, é citada a necessidade de o país se tornar mais atrativo para os negócios e para o trabalho. $\mathrm{O}$ documento salienta que a internacionalização da educação superior, a pesquisa e os sistemas de inovação estão no centro da renovação da sociedade. Além disso, a internacionalização das instituições promove a diversidade da sociedade e da comunidade de negócios, o networking internacional, a competitividade, a inovação no aumento de competência da educação de seus cidadãos. Para a Finlândia, a internacionalização das IES é também uma forma de o país se envolver na solução de problemas globais (FINLAND, 2009).

Também a Espanha, o Reino Unido e a Alemanha, países que apresentam fortes índices de internacionalização de seu sistema universitário produziram documentos estratégicos nacionais, propondo direções sobre os rumos da internacionalização da educação superior. A maioria dos documentos estabelece as ações necessárias para a modernização e melhoria da qualidade do sistema universitário, contemplando o âmbito da internacionalização como área estratégica para o desenvolvimento desses países. ${ }^{12}$

Na Alemanha, o documento Strategy of the Federal and Länder Ministers of Science for Internationalization of Higher Education Institutions estabeleceu nove grandes áreas de atuação para a promoção da internacionalização das instituições de Ensino Superior alemãs: estratégias individuais de internacionalização respeitando os objetivos e o perfil de cada IES; melhorias nos aspectos legais e burocráticos de validação de créditos e de documentos, reconhecimento de títulos; estabelecimento de uma cultura de boas-vindas, fortalecendo a integração social de estudantes, de professores e de pesquisadores; estabelecimento de um campus

${ }^{11}$ Os Planos Nacionais de Desenvolvimento da Colômbia norteiam uma política pública de internacionalização da educação superior. O Plano Nacional de Desenvolvimento de 2010-2014: Prosperidade para Todos tem definido ações claras para garantir o crescimento sustentável, a igualdade de oportunidades e a consolidação da paz através da inovação científica e produtiva, do bom governo, da sustentabilidade ambiental com o fim de contribuir para o objetivo nacional do posicionamento do país no contexto internacional.

12 Os documentos: Estrategia de Internacionalización del Sistema Universitario Español (http://www.mecd.gob.es/); The Value of Transnational Education to UK (https://www.gov.uk) e, ainda, Strategy of the Federal and Lander Ministers of Science for Internationalization of Higher Education Institutions in Germany (http://www.bmbf.de/pubRD/Internationalisierungsstrategie_engl.Fassung.pdf) estão disponibilizados na web. 
internacional, através da promoção de programas interculturais, internacionalização curricular, disciplinas ministradas em língua inglesa; o incremento de programas de mobilidade estudantil; a ampliação da capacidade das instituições em tornarem a Alemanha um dos quatro melhores países aptos para captação de estudantes de todo o mundo; a atração de talentos para estudos temporários nas IES alemãs; a expansão da capacidade de cooperação internacional para pesquisas e o estabelecimento de cursos transnacionais, para dar maior visibilidade às instituições (ALEMANHA, 2013, tradução livre dos autores). Com essas diretrizes, as universidades alemãs compreendem o claro posicionamento do país e suas expectativas com relação à internacionalização dos sistemas de educação superior e envidam esforços conjuntos nessa direção.

Quadro 5 - Relação de países/documentos governamentais referentes à Internacionalização da Educação Superior

\begin{tabular}{|l|l|c|l|}
\hline \multicolumn{1}{|c|}{ País } & \multicolumn{1}{|c|}{ Nome do Documento } & Período & \multicolumn{1}{|c|}{ Responsável } \\
\hline Alemanha & $\begin{array}{l}\text { Strategy of the Federal and Länder Ministers of Science for } \\
\text { Internationalization of Higher Education Institutions in Germany }\end{array}$ & 2020 & $\begin{array}{l}\text { The Federal Government } \\
\text { and the Länder }\end{array}$ \\
\hline Colômbia & $\begin{array}{l}\text { Reflexiones para la política de internacionalización de educación } \\
\text { superior en Colombia. }\end{array}$ & $2014-2032$ & $\begin{array}{l}\text { Ministério de Educación } \\
\text { Nacional }\end{array}$ \\
\hline Espanha & $\begin{array}{l}\text { Estrategia de Internacionalización del Sistema Universitario } \\
\text { Español }\end{array}$ & $2015-2020$ & $\begin{array}{l}\text { Ministerio de Educación, } \\
\text { Cultura e Deporte }\end{array}$ \\
\hline Finlândia & $\begin{array}{l}\text { Strategy for the Internacionalization of Higher Education Institu- } \\
\text { tionsin Finland. }\end{array}$ & $2009-2015$ & Ministry of Education \\
\hline Reino Unido & \begin{tabular}{l} 
The Value of Transnational Education to United Kingdom \\
\hline
\end{tabular} & 2014 & $\begin{array}{l}\text { The Government of the } \\
\text { United Kingdom }\end{array}$ \\
\hline
\end{tabular}

Fonte: Elaborado pelos autores (2015).

\subsection{Parâmetro da visibilidade}

O parâmetro de visibilidade traz desafios ao país em melhorar sua imagem no Exterior de forma a chamar a atenção sobre as fortalezas de seu sistema de educação superior e por garantir uma oferta educativa de qualidade (MANJARRÉS; GONZÁLEZ, 2014).

O Brasil possui dificuldade de posicionar internacionalmente o sistema de garantia da qualidade de seus programas, através de acordos de reconhecimento mútuo de títulos e da acreditação internacional. Recentemente, foi aprovado pelo Conselho Nacional de Educação (2016) uma nova Resolução para o reconhecimento de títulos emitidos no exterior, desburocratizando os trâmites necessários. ${ }^{13}$

${ }^{13}$ A Resolução n. 3 do Conselho Nacional de Educação de junho de 2016 determinou os novos procedimentos para revalidação de diplomas emitidos no Exterior. 
A Colômbia, por meio do Plano Nacional de Desenvolvimento 2010-2014: prosperidade para todos, consagrou a Política Educativa 2010-2014: educação de qualidade o caminho para prosperidade, que identifica a internacionalização como forma de promover a inovação e a pertinência na educação superior. Da mesma forma, estipula um objetivo político relacionado à inserção da educação superior colombiana no ambiente internacional, mantendo condições de qualidade e pertinência. O documento ainda define três linhas estratégicas: promoção acadêmica do país, fortalecimento institucional e estabelecimento de mecanismos para a internacionalização. O governo colombiano deseja transformar o país até 2025, no país mais educado da América Latina (COLÔMBIA, 2011).

É urgente a necessidade de se avançar na construção de elementos norteadores da internacionalização da educação superior no marco dos instrumentos de política pública, o que exige uma revisão da própria política externa brasileira, enfatizando mais os temas educativos e científicos, assim como promovendo a abertura de oportunidades no âmbito educacional. Da mesma forma, exige-se da educação superior uma revisão das limitações estruturais que enfrenta o seu próprio sistema em matéria de internacionalização para que se possa definir fórmulas para o avanço nesse processo. ${ }^{14}$

No Brasil, desde o início do século XX, as universidades públicas e algumas privadas, principalmente as confessionais, estavam envolvidas em programas internacionais de desenvolvimento que posteriormente evoluíram para projetos de pesquisa conjunta e de fortalecimento institucional, num modelo tradicional de cooperação, muitas vezes não simétrico, sem margens para qualquer possibilidade de colaboração institucional madura. Entretanto, esses programas se constituíram como um dos primeiros instrumentos formais de internacionalização da educação superior no Brasil.

Na perspectiva de Lima e Contel (2009, p. 157) é possível afirmar que desde 1930 até hoje o processo de internacionalização no Brasil sofreu sucessivas modificações. Essas modificações foram decorrentes de fatores internos, tais como: heterogeneidade do sistema de educação superior brasileiro, descontinuidade política entre diferentes governos, transformação de necessidades identificadas e consequente alteração de motivações que justificavam investimento em política de internacionalização, a maior ou menor disponibilidade de recursos fi-

\footnotetext{
${ }^{14}$ As limitações estruturais enfrentadas pelas IES brasileiras são inúmeras: desde a ausência de sensibilização da comunidade acadêmica; atitudes passivas por parte do corpo docente e discente das instituições ante a importância da internacionalização para o país; inexistência de estratégias claras para a internacionalização e para as relações interinstitucionais em grande parte das IES; falta de reconhecimento das diferenças culturais e da compreensão da importância da diversidade cultural; indisponibilidade ou inviabilidade de adaptação das comunidades estrangeiras; barreiras linguísticas; ausência de articulação política, entre outros.
} 
nanceiros e ainda os de caráter externo como: interesse de natureza acadêmica, política e econômica.

Desde 2011, o Governo brasileiro, através de suas agências de fomento, Capes e CNPq, gerencia o Programa Ciências sem Fronteiras. O programa está alicerçado numa proposta para a formação de recursos humanos em universidades estrangeiras de alto nível, visando promover a internacionalização da ciência e tecnologia nacional, estimular pesquisas que gerem inovação e, consequentemente, aumentar a competitividade das empresas brasilei$\operatorname{ras}^{15}$ (BRASIL, 2011b).

O governo federal investiu $\mathrm{R} \$ 3,16$ bilhões de reais, sendo $\mathrm{R} \$ 1,7$ bilhões da Capes (40 mil bolsas) e $\mathrm{R} \$ 1,4$ bilhões do CNPq (35 mil bolsas). Há também recursos da iniciativa privada. O Programa também tem como objetivo atrair estudantes e acadêmicos para além das fronteiras, num esforço de aumentar a visibilidade do país e das instituições de pesquisa.

O documento Brasil (2011a) salienta que o Programa Ciências sem Fronteiras não pretende revolucionar o sistema, mas sim lançar experimentalmente a semente do início da transformação estratégica na formação de recursos humanos especializados e preparados para as necessidades do desenvolvimento nacional ao expor os estudantes brasileiros a um ambiente de alta competitividade e empreendedorismo (BRASIL, 2011a).

Segundo o documento da Secretaria da Educação Superior do Ministério da Educação há o entendimento de que programas integrados de internacionalização permitem a elevação das universidades a padrões de classe internacional, propiciando o aumento da visibilidade e da articulação em nível global, qualificando a produção de conhecimento e a formação de pessoal capacitado, necessário ao desenvolvimento e à soberania nacional. ${ }^{16}$

O Programa Ciências sem Fronteiras apresenta resultados positivos, pois garantiu a oportunidade para milhares de alunos brasileiros vivenciarem pela primeira vez uma experiência acadêmica no Exterior e, com isso, tornou as Instituições de Ensino Superior do Brasil um pouco mais conhecidas, inserindo-as no cenário da educação mundial. Apesar disso, ao

\footnotetext{
${ }^{15}$ O Programa Ciências sem Fronteiras também estimula a mobilidade de pesquisadores, cientistas, estudantes de graduação e de pós-graduação para períodos de intercâmbio no Exterior. Seu principal objetivo é a mobilidade internacional de estudantes de graduação, pós-graduação, cursos técnicos, tecnólogos, de pessoal das empresas, docentes e pesquisadores. A mobilidade deveria contribuir para o desenvolvimento de projetos conjuntos de pesquisa e para a formação de redes. Também fomenta o desenvolvimento do empreendedorismo, da competitividade e da inovação no país. A meta é capacitar no exterior 101.000 bolsistas até 2015 por meio da Capes e do CNPq.

16 O programa Ciências sem Fronteiras é avaliado por dois comitês: o Comitê de Acompanhamento e Assessoramento do Programa e o Comitê Executivo do Programa. Fazem parte dos Comitês a Casa Civil da Presidência da República, o Ministério de Educação, o Ministério da Ciência e Tecnologia e Inovação, a Capes, o CNPq, representantes do setor privado, o MRE, bem como outros ministérios.
} 
longo do desenvolvimento do Programa muitos problemas têm sido detectados, deixando transparecer as fragilidades do sistema de Ensino Superior brasileiro, especialmente no que diz respeito às ações de internacionalização.

Dentre os problemas detectados, encontram-se dificuldades em se ter os créditos cursados no exterior validados por instituições brasileiras, principalmente, devido à rigidez do sistema de Ensino Superior brasileiro em relação ao reconhecimento e ao aproveitamento de estudos. Há problemas na harmonização das estruturas curriculares no Brasil em relação às grades curriculares dos cursos de graduação das IES estrangeiras (STALLIVIERI, 2015).

O Brasil enfrenta, também, dificuldades na revalidação de títulos acadêmicos obtidos em instituições estrangeiras, na concessão das duplas titulações e na oferta de disciplinas em outros idiomas, que não o português. A oferta de disciplinas em outros idiomas facilitaria e estimularia a presença de estudantes estrangeiros, internacionalizando o campus das IES brasileiras e promovendo a internacionalização de duas vias que se espera (STALLIVIERI, 2015).

\section{Quadro 6 - Relação do número de bolsas implementadas em cada modalidade por meio do Programa} Ciências sem Fronteiras

\begin{tabular}{|l|c|}
\hline \multicolumn{1}{|c|}{ Modalidade } & Número de bolsas implementadas \\
\hline Graduação Sanduíche & 61.534 \\
\hline Doutorado Sanduíche & 7.792 \\
\hline Doutorado no Exterior & 2.680 \\
\hline Atração de Jovens & 341 \\
\hline Pós-Doutorado no Exterior & 4.291 \\
\hline Pesquisador Visitante & 612 \\
\hline Mestrado no Exterior & 556 \\
\hline
\end{tabular}

Fonte: Elaborado pelos autores a partir de BRASIL. Ministérios da Ciência, Tecnologia e Inovação. Ministério da Educação. Programa ciência sem fronteiras. 2011b. Disponível em: <http://www.cienciasemfronteiras.cnpq.br/>. Acesso em: 19 nov. 2014.

No Ensino Superior brasileiro, fica evidente a falta do domínio, por parte dos estudantes e professores, de um segundo idioma, principalmente o inglês. Isso dificulta, por parte do Governo Federal, a coordenação para o preenchimento de vagas, por exemplo, do programa Ciências sem Fronteiras para países de língua inglesa. ${ }^{17}$ A baixa fluência no idioma inglês é o que limita, em grande medida, a visibilidade e a execução de diversas estratégias e ações que podem contribuir para a internacionalização da educação superior: a mobilidade estudantil,

\footnotetext{
${ }^{17} \mathrm{O}$ governo brasileiro acabou suspendendo a ida de alunos para Portugal, na Europa, pelo Programa CsF, pois grande parte dos alunos brasileiros acabava optando por esse país por não dominar uma segunda língua, gerando uma excessiva solicitação de bolsas para um mesmo destino.
} 
docente e administrativa, o trabalho em redes, a pesquisa conjunta, as duplas titulações, dentre outras.

Se o Brasil espera ter sucesso nos programas de educação internacional e impulsionar as iniciativas de internacionalização econômica, política, social, educacional e cultural, precisa desenvolver programas abrangentes para promover o multilinguismo (ARCHANJO, 2014).

Além disso, a internacionalização no Brasil se limita muito à mobilidade estudantil e é ainda baixa se comparada à mobilidade dos países desenvolvidos. As IES enfrentam obstáculos importantes para colocar em marcha iniciativas de mobilidade: limitações financeiras, programas de intercâmbio desequilibrados, normativa acadêmica complexa, além de dificuldades burocráticas para a obtenção de vistos de entrada nos países de destino (STALLIVIERI, 2015).

Com vistas à efetiva internacionalização, o Programa Ciências sem Fronteiras poderia proporcionar, de forma mais eficaz, a interação entre universidades e empresas a fim de aproximar o estudante dos postos de trabalho e melhor qualificá-lo, atendendo às novas exigências profissionais do mercado para atuação em ambientes globais e multiculturais. O Programa pode estabelecer diretrizes e se tornar uma robusta ferramenta de acompanhamento e fixação de padrões sobre como esse aluno intercambista irá contribuir para o desenvolvimento do país e para colaborar com a inovação das IES brasileiras ao retornar de sua experiência no Exterior. Até este estágio do Programa CsF, coube a cada IES desenvolver esse acompanhamento, porém, sem um controle mais rigoroso por parte do país e sem uma aferição mais acurada dos resultados obtidos com cada estudante em mobilidade, inviabilizando, dessa forma, uma melhor otimização dos resultados.

Destaca-se o fato de que um aluno da graduação tende a não agregar tanto ao país como um aluno de pós-graduação, que está inserido na pesquisa científica e é mais capaz, dado o desenvolvimento de seu perfil de pesquisador, de transferir o conhecimento aplicado por ocasião da sua volta ao país de origem, contribuindo para o avanço da inovação e da tecnologia. Grande parte das IES brasileiras está enviando alunos da graduação para o Exterior sem experiência na iniciação científica, uma vez que não é exigência do Programa. O resultado quanto à real contribuição desses alunos para a inovação e para o desenvolvimento do país precisa ser melhor avaliado com o tempo.

Acrescenta-se a isso tudo a fraca construção, formulação e execução de políticas institucionais com enfoque integral de internacionalização por parte das IES (HUDZIK, 2011). Poucas IES têm desenvolvido uma política de internacionalização que envolva diferentes atores com o relacionado às suas funções substantivas desde sua formulação até a sua execução. 
Esse fato coloca ainda mais em relevo a necessidade da construção de uma política conjunta, em nível nacional, que possa assessorar, orientar, estimular e capacitar às IES brasileiras em busca de um efetivo processo de internacionalização com vistas à qualidade educacional e respeitando as diferentes vocações institucionais e as diferenças regionais.

\subsection{Parâmetro de referência}

Sob o critério da referência, o desafio é elevar o sistema educativo das IES do Brasil correspondente aos melhores patamares do sistema educacional dos países desenvolvidos. É a partir do reconhecimento das práticas exitosas de outros países e de suas Instituições de Ensino Superior e da revisão dos mecanismos internos para sistematizar, visibilizar e avaliar os avanços da internacionalização que se terá uma referência mais pontual sobre as boas práticas de internacionalização que um país pode buscar (MENDIVELSO; RUEDA, 2014).

Para dar continuidade ao processo de internacionalização, ao impacto das políticas governamentais e à solidez das políticas e iniciativas adiantadas pelas IES, torna-se mister que seja incorporada uma dinâmica da medição como um componente transversal. Isto implica reconhecer e estudar os mecanismos de referência que existem tanto em nível nacional como internacional e aplicá-los ao sistema nacional (MANJARRÉS; GONZÁLEZ, 2014).

É importante analisar o amadurecimento da internacionalização no sistema de educação superior desde o âmbito das IES. A internacionalização implica na avaliação contínua da qualidade da sua oferta educativa, da solidez de suas políticas institucionais e da gestão da informação.

O Brasil também necessita enfrentar a medição de desempenho das IES com relação à internacionalização da educação superior a partir dos rankings internacionais, da acreditação de alta qualidade e dos sistemas nacionais e internacionais de avaliação de estudantes.

Mesmo sendo um tema polêmico, muitos países enfatizam a importância dos rankings internacionais e os incorporam dentro de suas estratégias de promoção, visibilidade e comunicação. Hoje, a participação das universidades brasileiras em rankings internacionais é ainda incipiente (NUNES, 2014b). ${ }^{18}$

\footnotetext{
18 Sabe-se que os rankings cobrem apenas algumas das missões da universidade. A maioria não contempla a diversidade de tipos institucionais e das múltiplas missões das instituições de educação superior. Muitos consideram que os rankings tornam as universidades mais transparentes. Por outro lado, as próprias metodologias adotadas carecem de transparência. É muito difícil acompanhar o cálculo das pontuações dos indicadores e, desses, para a pontuação geral, somente com as informações disponíveis publicamente. (NUNES, 2014a)
} 
É importante que o Brasil melhore a captura de informação por meio do Ministério da Educação e incorpore novas variáveis que deem conta desse processo, assim como gere articulação entre os diferentes sistemas de informação nacionais e internacionais. Essas ações permitem melhorar a análise de dados, sensibilizar e assessorar as IES para que reconheçam a importância da gestão da informação e seu impacto na eficiência e na gestão do processo de internacionalização (JARAMILL et al., 2005).

\subsection{Parâmetro de sustentabilidade}

O critério de sustentabilidade torna-se um dos mais relevantes, na medida em que consolida a política de internacionalização, pois outorga a essas iniciativas um alinhamento claro, uma maior articulação, obrigatoriedade, financiamento e uma visão a longo prazo (MANJARRÉS; GONZÁLEZ, 2014).

A avaliação dos recursos que se destinam à internacionalização deve levar em conta outros aspectos como melhorar a eficiência dos recursos atuais destinados à internacionalização, ampliar a visibilidade dos resultados dos investimentos e agregar esforços para ampliar a cobertura e o impacto dos mesmos.

É preciso também pensar em outras formas de se encontrar financiamento que vincule, além das tradicionais formas de cooperação internacional, representantes do setor privado, principalmente as empresas. Além de todos esses aspectos, a sustentabilidade da política requer um processo posterior de apropriação das IES e outras entidades do setor que legitimem as propostas planejadas. Para isso, seria importante avaliar a continuidade dos processos de acompanhamento para a implementação das políticas institucionais.

Na América Latina, a Colômbia vem se destacando como um país que adotou um processo governamental de acompanhamento na criação e fortalecimento de políticas institucionais para a gestão da internacionalização por meio do Ministério da Educação, através da criação de espaços de capacitação que nos últimos anos se deu em diferentes regiões do país. $\mathrm{O}$ impacto de ações, seminários e capacitações tem por um lado um alcance limitado, por isso o Ministério da Educação colombiano optou por disseminar um modelo de assessoria e transferência de conhecimento denominado Programa de Acompanhamento (COLÔMBIA, 2011). ${ }^{19}$

\footnotetext{
19 O Programa foi implementado pelo Ministério da Educação da Colômbia com uma metodologia que contempla a assessoria e o acompanhamento por parte das IES que contam com acreditação de alta qualidade a instituições com menor nível de desenvolvimento. O Programa inclui o intercâmbio de boas práticas, assessoria sobre modelos institucionais de construção de políticas, planos e gestão da internacionalização.
} 
Iniciativas como essa podem servir de sugestão ao governo brasileiro, que já possui capacidades intelectuais instaladas nos escritórios, assessorias, coordenadorias de relações acadêmicas internacionais nas próprias universidades brasileiras, que contam com profissionais altamente qualificados e especializados no tema da internacionalização da educação superior e que podem ser os protagonistas de um movimento sólido em direção a avanços para um novo patamar para a internacionalização que o país necessita e merece.

\section{Considerações finais}

A internacionalização é causa e consequência do sistema emergente. É frequentemente confundida com globalização, pois enquanto a globalização pode ser inalterável, a internacionalização envolve muitas escolhas (ALTBACH; KNIGHT, 2007).

A internacionalização da educação superior brasileira é recente, ainda que nos anos 50, com a criação das principais agências de fomento, já houvesse iniciativas de cooperação internacional entre universidades (LIMA; CONTEL, 2009). Conforme é possível identificar nos documentos nacionais o incentivo ao processo de internacionalização das Instituições de Ensino Superior foi muito reativo e nunca esteve fixado na raiz de uma política pública, com diretrizes mais ousadas no sentido de definir os rumos que o país quer seguir com a internacionalização da educação superior.

No âmbito governamental, a promoção da internacionalização das IES necessita ter significado estratégico para o país. Os documentos não apontam esse objetivo de uma forma mais explicita. Apenas observa-se menções no sentido da busca do desenvolvimento para o país, formação de recursos humanos e promoção da pesquisa principalmente em C\&T. A abertura das universidades brasileiras para o mundo carece de mais reciprocidade, no sentido de levá-las à modernização e à inovação a partir da cooperação internacional entre diferentes países para, consequentemente, promover o desenvolvimento nacional. Ainda muito do que se faz por meio da cooperação internacional não é de mão dupla, não contempla os critérios de reciprocidade, beneficiando geralmente apenas um dos parceiros.

Para a construção de uma política pública para a internacionalização das Instituições de Ensino Superior brasileiras é preciso definir critérios, estabelecer elementos de discussão como identidade, institucionalidade, visibilidade, referência e sustentabilidade (MANJARRÉS; GONZÁLEZ, 2014), e que respondam à construção de um projeto de Estado conforme apontado no decorrer deste estudo. 
Não se observa isso de forma consistente nos documentos analisados no Brasil. Identifica-se que há motivações econômicas, políticas, acadêmicas e socioculturais no suporte ao desenvolvimento econômico e tecnológico do país, carecendo ainda de indicações claras sobre as formas que a internacionalização da educação superior, a partir dessas motivações, contribuirá para o fortalecimento da posição internacional do Brasil no sistema mundial da educação. Ou seja, não é possível identificar como o país estrategicamente pretende se fazer presente de forma ativa no cenário internacional da educação, por meio da participação de seu sistema de Ensino Superior.

A ausência de um documento geral, de âmbito nacional, que oriente a formulação e a execução de políticas nacionais e regionais para a internacionalização da educação superior dificulta os avanços na área, o que interfere, também, na sua conceitualização para um país com as características econômicas, geográficas, linguísticas do Brasil e na definição dos seus parâmetros de qualidade.

Somente a partir da construção de uma agenda positiva, do estabelecimento do diálogo constante e profícuo, da discussão e da elaboração de um documento nacional que envolva esses principais atores é que se irá produzir uma compreensão e uma visão de longo prazo sobre os objetivos estratégicos que a internacionalização da educação superior pode representar para o futuro e para a projeção do país em termos de inserção internacional.

\section{Referências}

ALEMANHA. The Federal Government and the Länder. Strategy of the Federal and Länder Ministers of Science for the Internationalisation of the Higher Education Institutions in Germany. 2013. Disponível em: http://docplayer.net/3105179-Strategy-ofthe-federal-and-lander-ministers-of-science-for-the-internationalisation-of-the-highereducation-institutions.html. Acesso em: 10 abr. 2015.

ALTBACH, P.; KNIGHT, J. The internationalization of higher education: motivations and realities. Journal of studies in international education, Amsterdam v. 11, n. 3-4, p. 290305, 2007.

ARCHANJO, R. Languages... what for? Birkbeck Comments. London: University of London, 2014. Disponível em: <http://blogs.bbk.ac.uk/bbkcomments/2014/12/04/languageswhat-for/> Acesso em: 4 dez. 2014.

AVEIRO, T. O Programa Ciências sem Fronteiras como ferramenta de acesso à mobilidade internacional. 2014. \#Tear: revista educação, ciência e tecnologia, Canoas, v. 3, n. 2, p. 1-21, 2014.

AYLÓN, B. La cooperación de Brasil: un modelo en construcción para una potencia emergente. 2010. Disponível em:

<http://www.realinstitutoelcano.org.wps/portal/rielcano/contenido?WCM_GLOB

AL_CONTEXT=/elcano_es/zonas_es/ari143-2010>. Acesso em: 26 dez. 2014. 
BRASIL. Conselho Nacional de Desenvolvimento Científico e Tecnológico - CNPQ. Demanda de atendimento. 2013. Disponível em: <http://www.cnpq.br/demanda-eatendimento>. Acesso em: 15 abr. 2015.

BRASIL. Conselho Nacional de Desenvolvimento Científico e Tecnológico. Acordos. 2014. Disponível em: <http://cnpq.br/acordos>. Acesso em: 10 abr. 2015.

BRASIL. Coordenação de Aperfeiçoamento de Pessoal de Nível Superior - CAPES. Cooperação internacional. 2008. Disponível em: < http://www.capes.gov.br/cooperacaointernacional>. Acesso em: 08 mar. 2015.

BRASIL. Ministério da Ciência, Tecnologia e Inovação. Conselho Nacional de Desenvolvimento Científico e Tecnológico. Coordenação de Aperfeiçoamento de Pessoal de Nível Superior - Programa ciências sem fronteiras: um programa especial de mobilidade internacional em ciência, tecnologia e inovação. Documento Conjunto Capes - CNPq. 2011a. [Digitalizado]

BRASIL. Ministério das Relações Exteriores. Agência brasileira de cooperação. Acordos vigentes da cooperação técnica entre países em desenvolvimento - CGPD. 2012. Disponível em: <http://www.abc.gov.br/CooperacaoTecnica/AcordosVigentes/CGPD>. Acesso em: 08 mar. 2015.

BRASIL. Ministérios da Ciência, Tecnologia e Inovação. Ministério da Educação. Programa ciência sem fronteiras. 2011b. Disponível em: 〈http://www.cienciasemfronteiras.cnpq.br/>. Acesso em: 19 nov. 2014.

CANEDO, L., GARCIA, A. Les Boursiers Brésiliens et l'accès aux formations d'excellence internacionales. Cahuers du Brasil Contemporain, Paris, n. 57/58, p. 21-48, 2004-2005.

CARVALHO, A. A. de. Cooperação Internacional em Educação Superior. In: SEMINÁRIO. INTERNACIONALIZAÇÃO: Desafio para Universidade, 1. 2014. Porto Alegre. Anais... Porto Alegre, 2014. Disponível em:<http://www.pucrs.br/eventos/internacionalizacao/ downloads/22.10-cooperacao-internacional-em-educ.-superior-almerinda-a-de-carvalho.pdf $>$. Acesso em: 8 dez. 2014.

COLÔMBIA. Hacia la prosperidad democrática: visión 2010-2014. In: COLOMBIA. Plan nacional de desarrollo 2010-2014: Prosperidad para todos. Bogotá. 2011.

CONSELHO NACIONAL DE EDUCAÇÃO - CNE. Resolução n. 3. Disponível em: $<$ http://www.capes.gov.br/images/stories/download/legislacao/resolucaoCNE-03-de-22-062016.pdf>. Acesso em: 23 ago. 2016.

CROSS, M.; MHLANGA, E.; OJO, E. Emerging concept of internationalization in south African higher education: conversations on local and global exposure at the university of the Witwatersrand (WITS). Journal of studies in international education, Amsterdam, v. 15, n.1, p. 75-92, 2011.

DEARDORF, D. et al (Orgs.). The sage handbook of international higher education. Califórnia, USA: Sage publications, 2012.

ESPANHA. Ministerio de Educación, Cultura y Deporte. Estrategia para la internacionalización de las universidades españolas 2015 - 2020. 2014. Disponível em: < http://www.mecd.gob.es/educacion-mecd/dms/mecd/educacion-mecd/areaseducacion/universidades/politica-internacional/estrategiainternacionalizacion/EstrategiaInternacionalizaci-n-Final.pdf>. Acesso em: 10 abr. 2015. 
Helsinki: Ministry of Education, 2009. Disponível em:

<http://www.minedu.fi/OPM/Julkaisut/2009/liitteet/opm23.pdf>. Acesso em: 27 dez. 2014.

FRANCO, M. E; MOROSINI, M. Marcos regulatórios e arquiteturas acadêmicas na expansão da educação superior brasileira: movimentos indutores. Revista Educação em Questão, Natal, v. 42, n. 28, p.149-174. 2012.

FRANCO, M. E; MOROSINI, M; OLIVEN, A. C; DEUS, M.A.P; ZANETTINI-RIBEIRO, C. Expansão da educação superior e arquiteturas acadêmicas: tensões e desafios. SérieEstudos, Campo Grande, v. 30, p. 117- 139, jul./dez. 2010.

FRANCO, R.; COHEN, E. Evaluación de proyectos sociales. México: Siglo XXI, 1992.

GIL, A. C. Como elaborar projetos de pesquisa. 5. ed. São Paulo: Atlas, 2010.

HUDZIK, J. Comprehensive internationalization: from concept to action. Washington, DC: NAFSA Association of International Educators, 2011.

JARAMILL, H. et al. Hacia un sistema nacional de educación superior. Bogotá, D.C.: Centro Editorial Universidad del Rosario, 2005.

LASTRES, H. M. M; FERRAZ, J. C. Economia da informação, do conhecimento e do aprendizado. In: LASTRES, H. M. M.; S. ALBAGLI (Orgs.). Informação e globalização na era do conhecimento. Rio de Janeiro: Campus, 1999. Cap. 1.

LAUS, S. P.; MOROSINI, M. L'internationalisation de l'enseignement supérieur au Brésil. In: WIT, H, et al. (Org.). L'enseignement supérieur en Amérique Latine. La dimension internationale. Washington: OCDE, 2005.

LIMA, M. C.; CONTEL, F. B. Períodos e motivações da internacionalização da Educação Superior. In: COLLOQUE DE 1' IFBAE, 5., 2009, Grenoble. Anais... Grenoble, 2009. Disponível em: <http://www.ifbae.com.br/congresso5/pdf/B0095.pdf>. Acesso em: 15 dez. 2014.

MANJARRÉS, N. J.; GONZALEZ, C. A. Elementos para la construcción de uma política pública de internacionalización de la educación superior. In: SALMI, J. et al. (Orgs.)

Reflexiones para la política de internacionalización de la educación superior en

Colombia. Bogotá: Ministerio de Educación Nacional, 2014. Disponível em:

$<$ http://ocyt.org.co/es-es/noticias/ArtMID/478/ArticleID/222/Reflexiones-para-la-pol237ticade-internacionalizaci243n-de-la-educaci243n-superior-en-Colombia> p. 267-283. Acesso em: 27 dez. 2014.

MENDIVELSO, F.T.; RUEDA, C.H.L. Elementos para la construcción de uma política pública de internacionalización de la educación superior. In: SALMI, J. et al. (Orgs.).

Internacionalización y calidad en Colombia: el rol estratégico de la acreditación en el fortalecimiento de los procesos de internacionalización de la educación superior. Bogotá: Ministerio de Educación Nacional, 2014. Disponível em:<http://ocyt.org.co/eses/noticias/ArtMID/478/ArticleID/222/Reflexiones-para-la-pol237tica-deinternacionalizaci243n-de-la-educaci243n-superior-en-Colombia> p. 267-283. Acesso em: 16 out. 2016.

NUNES, E. Educação superior sem rumo. Boletim comunitário, Rio de Janeiro, 22 dez. 2014a. Disponível em:< http://www.ucam.com.br/\#!educacao-superior-sem-rumo/cukh>. Acesso em: 20 abr. 2015

NUNES, E. Rankings internacionais: a irresistível polêmica em torno de seus sentidos e metodologias. Revista Ensino Superior, Campinas, n. 12, jan./fev. 2014b. Disponível em: 
$<$ http://www.revistaensinosuperior.gr.unicamp.br/artigos/rankings-internacionais-airresistivel-polemica-em-torno-de-seus-sentidos-e-metodologias>. Acesso em: 24 dez. 2014.

OFFE, C. Problemas estruturais do Estado capitalista. Rio de Janeiro: Tempo Brasileiro, 1984.

RICHARDSON, R. J. Pesquisa social: métodos e técnicas. São Paulo, Atlas, 1999.

SALMI, J. et al. (Orgs.). Reflexiones para la política de internacionalización de la educación superior en Colombia. Bogotá: Ministerio de Educación Nacional, 2014.

SECCHI, L. Políticas públicas: conceitos, esquemas de análise, casos práticos. 2. ed. São Paulo: Cengage Learning, 2013.

STALLIVIERI, L. Estratégias de internacionalização das universidades brasileiras. Caxias do Sul: Educs, 2004.

STALLIVIERI, L. Brazil's Science Without Borders Program. The World View. Disponível em:

https://www.insidehighered.com/blogs/worldview/brazilssciencewithoutbordersprogram.Aces so em: 31 maio 2015.

WIT, H. Internationalization of higher education in the United States of America and Europe: a historical, comparative and conceptual analysis. Boston: Library of Congress, 2002.

José Alberto Antunes de Miranda - Centro Universitário La Salle Canoas | RS | Brasil. Contato: antunes@unilasalle.edu.br

Luciane Stallivieri - Universidade Federal de Santa Catarina Florianópolis | SC | Brasil. Contato: luciane.stallivieri@ufsc.br 